\title{
Assessment of Self-Determination in Adolescents with Neonatal Brachial Plexus Palsy
}

\author{
Donna Bergman, EdD, Lynnette Rasmussen, OTRL, Kate Wan-Chu Chang, MA, MS, \\ Lynda J-S. Yang, MD, PhD, Virginia S. Nelson, MD, MPH
}

\begin{abstract}
Background: The term self-determination refers to decision-making, goal setting, and perseverance to achieve those goals. Numerous studies have established the importance of self-determination to enhance learning and improve postschool outcomes. However, most studies evaluate students with learning disabilities, cognitive impairment, or behavioral disabilities. There is an absence of research on self-determination for adolescents with physical disabilities.

Objective: To assess self-determination of adolescents with neonatal brachial plexus palsy (NBPP) compared with their typically developing peers via self-reported measures of function.

Design: Case-control study.

Setting: Brachial plexus clinic.

Participants: Twenty adolescents with NBPP (aged 10-17 years) and their parents and 20 age/gender-matched typically developing adolescents and their parents were recruited. Non-English-speaking participants and those with other physical impairments were excluded from study.

Methods: Participants completed demographic and American Institutes for Research (AIR) self-determination surveys. One of two designated occupational therapists evaluated participant physical function.

Main Outcome Measurements: A demographic survey and AIR self-determination assessment were administered, and active range of motion measurements in shoulder forward flexion, elbow flexion, elbow extension, forearm pronation, and supination were obtained. Grip/pinch strength, MRC muscle strength, 9-Hole Peg Test, and Mallet scale scores also were evaluated.

Results: Despite physical differences, adolescents with NBPP presented similar self-determination levels as their typically developing peers. Adolescents with NBPP rated their opportunities to engage in self-determined behaviors at school significantly lower than at home. Both adolescents with NBPP and those in the control group rated their opportunities to engage in selfdetermined behaviors at school significantly lower than at home.

Conclusions: Adolescents with NBPP presented similar self-determination scores as their age/gender-matched typically developing peers. These results could be a reflection of our program's patient- and family-centered care approach. Therefore, caregivers and providers should encourage personal development and fulfillment in adolescents with NBPP. Teachers and schools should be aware that opportunities for acquiring self-determination skills might be more limited at school than at home in this age group.

Level of Evidence: III
\end{abstract}

\section{Introduction}

Neonatal brachial plexus palsy (NBPP) occurs during the perinatal period and manifests as a loss of movement and sensation of the arm as a result of damage to nerves of the brachial plexus. NBPP affects approximately 0.1-5.1 per 1000 live births [1-4]. The majority of infants will recover without any intervention, but $5 \%-25 \%$ will have persistent NBPP with continuing functional deficits of the arm [5].
Adolescents with persistent deficits may demonstrate muscle imbalance, joint or soft-tissue contractures, arm length and circumference differences, and atrophy [6]. Differences in appearance from normally developing peers include arm length discrepancy, sloping shoulder or protruding scapula, and muscle atrophy.

As the result of functional limitations, adolescents with persistent NBPP may have difficulties with activities of daily living [7-9]. The current literature $[7,8,10]$ indicates that 
physical limitations have a negative correlation, with International Classification of Functioning, Disability and Health measures of activity and participation that can influence the development, quality of life, and self-esteem in adolescents [7-9]. Level of participation and other considerations, such as psychosocial factors, also may be affected in the context of persistent functional impairments.

An area yet unexplored in adolescents with NBPP is self-determination (SDet). SDet refers to the process by which a person controls his or her own life. Ward [11] further defined the concept as "both the attitudes which lead people to define goals for themselves and their ability to take the initiative to achieve these goals." SDet is a foundational element of "transition to adulthood" and is essential to postschool success in employment, social, and family interactions [12-14]. A published method for determining SDet is the American Institutes for Research (AIR) Self-Determination Scale [15]. We sought to evaluate the SDet of adolescents with NBPP (1) by using the AIR self-determination assessments to evaluate SDet in adolescents with NBPP and (2) by comparing the SDet of adolescents with NBPP to their typically developing peers in the context of physical function.

\section{Methods}

\section{Study Design and Participants}

This prospective case-control study was conducted from February to August 2014. We recruited 20 adolescents from the specialty brachial plexus program at a tertiary care referral center with diagnosed NBPP (aged 10-17 years) and their parents (NBPP group), sequentially during routine clinic appointments. Gender- and age-matched typically developing adolescents and their parents (control group) were recruited subsequently through families of NBPP participants and our network of study team members. Consent was obtained from all parents, and assent was obtained from adolescents in both groups. Excluded from study were non-Englishspeaking participants and those with other physical impairments (eg, cerebral palsy). Institutional review board approval was obtained for the study protocol (HUM77336). Participants and parents finished demographic surveys and AIR self-determination assessments in the clinic visit. In addition, 1 of 2 designated occupational therapists evaluated the participants' physical function via active range of motion, grip and pinch strength, Medical Research Council (MRC) muscle strength, 9-Hole Peg Test, and Mallet scale score.

\section{Surveys}

\section{Demographic Survey}

Parents filled out the demographic survey, which included the following information: adolescent's age, gender, race, insurance, parents' education levels, family makeup, and NBPP-related factors (involved side, hand dominance, and Narakas classification scores). The basis for the Narakas classification of NBPP is clinical examination of the affected muscles of the arm during the first 8 weeks of life (Narakas I involves C5, C6; Narakas II involves C5, C6, and C7; Narakas III involves C5-T1; and Narakas IV involves C5-T1 with Horner syndrome).

\section{AIR Self-Determination Assessments}

Both adolescents and their parents completed the AIR self-determination assessments. A single trained researcher performed the scoring. The AIR selfdetermination assessments were developed by the AIR for all school-aged children [15]. The assessments produce a profile of a child's level of SDet and evaluate 2 broad SDet components-capacities (including ability and perception) and opportunities (at home and at school). The profile compares student, parent, and educator views in areas of abilities, perceptions, and opportunities at home and at school. Our study used the parent and student versions only, as this study did not involve educators in the classroom setting.

\section{Physical Assessment}

Participants were in a standing position during evaluation, except when performing the 9-Hole Peg Test (performed while seated). In both NBPP and control groups, assessments included right and left upper extremities. We compared physical assessment of the affected arm of the NBPP participant with the nondominant arm of a control group participant. Active range of motion measurements were obtained with a standard goniometer for shoulder forward flexion $\left(0-180^{\circ}\right)$, elbow flexion $\left(0-150^{\circ}\right)$, elbow extension $(-150$ to $\left.0^{\circ}\right)$, and forearm pronation and supination $\left(0-90^{\circ}\right)$. The MRC scale (grades $0-5$ ) was used to test and record muscle power of anterior deltoid, biceps, and triceps muscles. Assessment of shoulder abduction and external rotation was via the Mallet grading system for shoulder function (grades I through IV) [16]. Instruments for measuring grip and pinch strength included the Jamar hand dynamometer for grip, and the Jamar hydraulic pinch gauge (Asimov Engineering Co, Los Angeles, CA) to document maximum isometric strength (recorded in pounds). For all participants, the dynamometer was positioned in the second notch. Measurements from each upper extremity included grip strength, 3-point pinch, and lateral pinch The 9-Hole Peg Test was used to measure finger dexterity on both hands while the subject was sitting $[17,18]$.

\section{Statistical Analysis}

Participant demographics were calculated by the use of descriptive statistics and summaries. To compare responses from AIR self-determination assessment and physical measurements between NBPP and control 
groups, we used paired $t$-test for continuous variables and Wilcoxon signed rank test for ordinal variables. Probability values less than .05 were considered statistically significant. SPSS statistical software (version 18, SPSS Inc, Chicago, IL) was used to perform all statistical analyses.

\section{Results}

\section{Participant Demographics}

Mean age of participants was 13 years, with 6 male and 14 female subjects in both the NBPP and control groups. The majority of participants were white (70\% NBPP group; $95 \%$ control group). Twenty-five percent of the NBPP group and $10 \%$ of the control group had Medicaid insurance. Parental education levels were similar in NBPP and control groups (Table 1). Thirty-five percent of NBPP group and 80\% of control group were from 2-parent families. The affected

Table 1

Participant demographics

\begin{tabular}{|c|c|c|}
\hline & $\begin{array}{l}\text { NBPP Group } \\
(\mathrm{n}=20)\end{array}$ & $\begin{array}{l}\text { Control Group } \\
(n=20)\end{array}$ \\
\hline Age, $y$, mean $\pm S D$ & $13 \pm 2$ & $13 \pm 2$ \\
\hline \multicolumn{3}{|l|}{ Gender, n (\%) } \\
\hline Male & $6(30)$ & $6(30)$ \\
\hline Female & $14(70)$ & $14(70)$ \\
\hline \multicolumn{3}{|l|}{ Race, n (\%) } \\
\hline White & $14(70)$ & $19(95)$ \\
\hline African American & $5(25)$ & - \\
\hline Other & $1(5)$ & $1(5)$ \\
\hline \multicolumn{3}{|l|}{ Insurance, $\mathrm{n}(\%)^{*}$} \\
\hline Private & $14(70)$ & $18(90)$ \\
\hline $\begin{array}{l}\text { Children's special } \\
\text { health care services }\end{array}$ & $4(20)$ & - \\
\hline Medicaid & $5(25)$ & $2(10)$ \\
\hline Other insurance & $4(20)$ & $2(10)$ \\
\hline \multicolumn{3}{|l|}{ Mother's education, n (\%) } \\
\hline College graduate & $11(55)$ & $13(65)$ \\
\hline Some college & $7(35)$ & $3(15)$ \\
\hline High school & $2(10)$ & $4(20)$ \\
\hline \multicolumn{3}{|l|}{ Father's education, n (\%) } \\
\hline College graduate & $11(55)$ & $12(60)$ \\
\hline Some college & $8(40)$ & $2(10)$ \\
\hline High school & - & $4(20)$ \\
\hline Less than high school & $1(5)$ & $2(10)$ \\
\hline \multicolumn{3}{|l|}{ Family makeup, n (\%) } \\
\hline Mother and father & $7(35)$ & $16(80)$ \\
\hline Single parent & $12(60)$ & $4(20)$ \\
\hline Stepparent & $1(5)$ & - \\
\hline \multicolumn{3}{|l|}{ NBPP-affected side, $\mathrm{n}(\%)$} \\
\hline Left & $8(40)$ & - \\
\hline Right & $12(60)$ & - \\
\hline \multicolumn{3}{|c|}{ Hand/arm dominance, n (\%) } \\
\hline Left & $11(55)$ & - \\
\hline Right & $8(40)$ & $20(100)$ \\
\hline Bilateral & $1(5)$ & - \\
\hline \multicolumn{3}{|l|}{ Narakas grade, n (\%) } \\
\hline I-II & $8(40)$ & - \\
\hline III-IV & $12(60)$ & - \\
\hline
\end{tabular}

$\mathrm{NBPP}=$ neonatal brachial plexus palsy; SD = standard deviation.

* Four families of adolescents with NBPP and 2 control families had multiple types of insurance. arm was the right arm in 12 participants in the NBPP group. Comparisons of affected arm in NBPP versus the nondominant arm in control group and unaffected arm in NBPP versus the dominant arm in control group were assessed. Hand/arm dominance was determined by self-reporting of which hand was used primarily for most self-care and recreational activity. Sixty-three percent of the NBPP subjects were in the Narakas grade III-IV group.

\section{AIR Self-Determination Assessments}

For global SDet (Table 2), adolescents with NBPP had slightly greater scores than adolescents from the control group, with no significant difference $(P=.709)$. None of the subgroup analyses showed statistical significance between adolescents with NBPP and the control group. There were no significant differences between parents of adolescents with NBPP and parents in the control group on global SDet and subgroup comparisons (Table 3 ). When adolescents with NBPP and their parents were compared, adolescents reported greater ability to perform SDet behaviors than their parents did (Figure 1; 25.4 versus 22.0, respectively, $P=$.007). There were no significant differences in perceived opportunities at home and opportunities at school between NBPP adolescents and their parents (Figure 1). No significant difference was observed between control group adolescents and parents for any category (Figure 2).

Adolescents with NBPP rated their opportunities to engage in SDet behaviors at school significantly lower than at home (Table 4; 21.2 versus 27.1 , respectively; $P=.003$ ); however, from the perspective of parents of adolescents with NBPP, there was only a marginal difference (Table 4; 24.1 versus 26.1, respectively; $P=.069$ ). Opportunities to engage in self-determined behaviors at home were rated significantly greater than at school for both control group adolescents and parents (Table 4; $P=.014$ and .015 , respectively).

\section{Physical Assessments}

Physical assessments compared the affected arm of adolescents with NBPP versus the nondominant arm of

Table 2

Comparison of AIR self-determination assessment scores for adolescents in the NBPP and control groups

\begin{tabular}{llll}
\hline & $\begin{array}{l}\text { NBPP Group } \\
\text { Student } \\
\text { Scores }\end{array}$ & $\begin{array}{l}\text { Control Group } \\
\text { Student } \\
\text { Scores }\end{array}$ & $P$ Value \\
\hline Parameters & 83.0 & 81.5 & .709 \\
\hline Global self-determination & 51.2 & 47.8 & .227 \\
Capacity* & 25.4 & 24.0 & .326 \\
Ability & 25.8 & 23.8 & .232 \\
Perception & 48.3 & 50.0 & .534 \\
Opportunity & 27.1 & 26.8 & .785 \\
Home & 21.2 & 23.2 & .295 \\
School & & \\
\hline
\end{tabular}

AIR $=$ American Institutes for Research; NBPP $=$ neonatal brachial plexus palsy.

* Capacity on the AIR-Student form comprises Ability and Perception. 
Table 3

Comparison of AIR self-determination assessment scores for parents in NBPP and control groups

\begin{tabular}{llll}
\hline Parameters & NBPP Group Parent Scores & Control Group Parent Scores & $P$ Value \\
\hline Global self-determination & 80.4 & 80.0 & .941 \\
Ability $^{*}$ & 22.0 & 22.0 & .961 \\
Opportunity & 50.2 & 49.5 & .693 \\
Home & 26.1 & 25.8 & .684 \\
School & 24.1 & 23.8 & .775 \\
\hline
\end{tabular}

AIR = American Institutes for Research; NBPP = neonatal brachial plexus palsy.

* The AIR-Parent form contains only Ability scores and not Perception, which refers to the student's feelings about self-determination.

control group participants. Statistically significant differences existed for active range of motion, grip, pinch, and muscle strength (Table 5). For example, mean active shoulder forward flexion of adolescents with NBPP was $80^{\circ}$ less than control group $(P<.0001)$, and elbow flexion was $28^{\circ}$ less than control group $(P=.0002)$. Mean forearm supination of NBPP adolescents was $44^{\circ}$ compared with $90^{\circ}$ in the control group $(P=.0004)$. The grip strength difference between NBPP and control group was 18 pounds $(P=.002)$. However, the 9-Hole Peg Test showed no statistically significant difference when NBPP and control groups $(P=.24)$ were compared. Median scores were reported for the manual muscle tests (MRC range 2-5). For NBPP groups, anterior deltoid was $2 / 5$, with $3 / 5$ for biceps and triceps; control group rated $5 / 5$ in all 3 areas measured.

Comparison of Mallet scores (range II-IV) in NBPP versus control groups showed significant differences in all movements $(P<.0001)$. Control group scores for all 5 movements were normal, whereas for the NBPP group, the median scores for abduction, exorotation, and hand-to-back were II, and the median scores for handto-head as well as hand-to-mouth movements were III.

\section{Discussion}

SDet involves a combination of skills, knowledge, and beliefs that ultimately enable a person to engage in goal-driven, self-regulated, and autonomous behavior. SDet has become an important research area for adolescents with chronic conditions and disabilities.

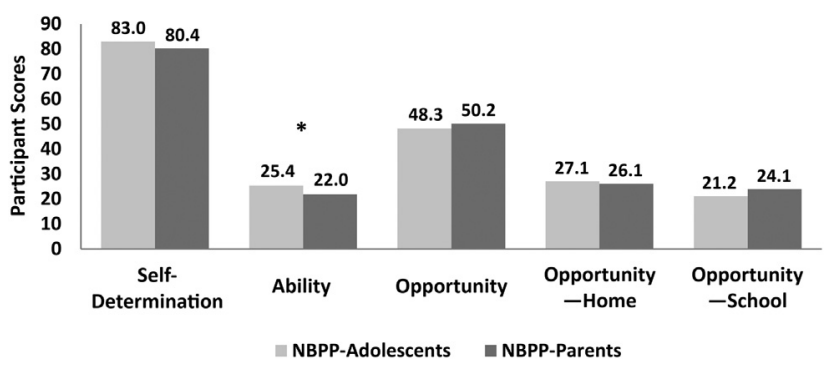

Figure 1. Comparison of American Institutes for Research assessment scores for adolescents with neonatal brachial plexus palsy (NBPPAdolescents) vs parents of adolescents with neonatal brachial plexus palsy (NBPP-Parents), revealing a statistically significant difference in scoring on the Ability category $\left({ }^{*} P=.007\right)$.
Previous studies have investigated the relationships between the various components and applications in numerous patient disabilities. For example, McDougall et al [14] compared the relationship between SDet and perceived quality of life in youth and young adults with chronic conditions, such as spina bifida, cerebral palsy, and acquired brain injury. Their investigation suggested that essential components of SDet, such as autonomy, self-regulation, self-realization, and psychological empowerment significantly impact quality of life. A more recently published collaborative study looked at the relationship of injury severity, social support, coping strategies, and self-concept in youth with NBPP [19]. The investigators asked whether a relationship existed between severity of injury, social difficulties, and selfconcept, and they concluded youth with NBPP were functioning well in those areas. In fact, the authors found that youth with NBPP had significantly greater self-concept ratings compared with their typically developing peers. The authors defined self-concept as how one perceives oneself, whereas SDet refers to more outward behaviors of self-regulated, autonomous behaviors.

SDet can be more complex and multifaceted than self-concept. Each area of SDet can affect the success of adolescents entering adulthood. In our study, we evaluated and found no differences in SDet between adolescents with NBPP and age/gender-matched typically developing peers, despite the functional differences. Potential reasons for the lack of difference in SDet include proactive participation in daily activities, increased opportunity for family support, and frequent

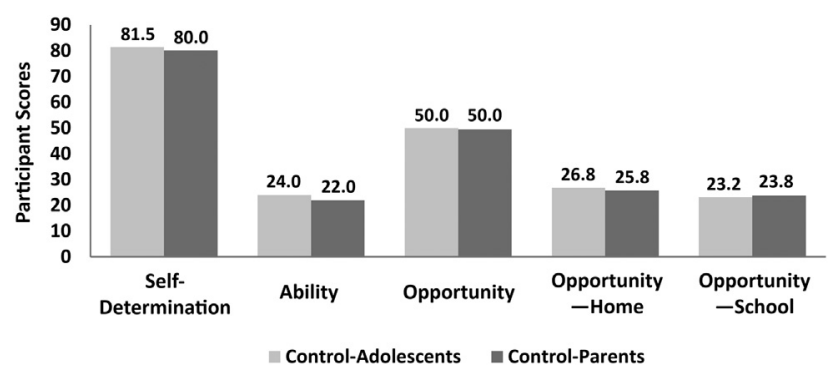

Figure 2. Comparison of American Institutes for Research assessment scores for control group adolescents (Control-Adolescents) vs control group parents (Control-Parents). 
Table 4

Comparison of AIR self-determination assessment ratings for opportunities to engage in self-determined behaviors at home and school

\begin{tabular}{llll}
\hline Parameters & Opportunities at School & Opportunities at Home & $P$ Value \\
\hline Adolescents with NBPP & 21.2 & 27.1 & .003 \\
Parents of adolescents with NBPP & 24.1 & 26.1 & .069 \\
Control adolescents & 23.2 & 26.8 & .014 \\
Control parents & 23.8 & 25.8 & .015 \\
\hline
\end{tabular}

$\mathrm{AIR}=$ American Institutes for Research; NBPP = neonatal brachial plexus palsy.

involvement with health care workers during NBPP treatment. From our clinical work with adolescents with NBPP, we have observed that they take part in general activities such as sports participation, attending college, living independently, and securing employment. Likewise, Strombeck and Fernell [20] compared adolescents with NBPP with their able-bodied peers in activities and participation in daily life and concluded that adolescents with NBPP live a typical and average teenage life.

Another opportune area for cultivating SDet skills is the family environment. Harrison et al [21] reported the need for families to be aware of and involved with providing opportunities to promote SDet in persons with disabilities. Youth can develop SDet and self-regulation skills through day-to-day choices, household chores, and occasions to deal with failure. Finally, youth with NBPP also can have an additional opportunity for psychosocial interaction with health care providers. In our clinical experience, most NBPP patients/families voluntarily participate in the activities of our interdisciplinary program. Communication to address goals and interventions involves the treatment team, the patient, and the family. Our program is based on the patient- and family-centered care approach and is committed to collaboration with patients and families in caring for the patient [22]. If patients are in therapy, they are involved in establishing goals and working to achieve them, which includes responsibility for a home exercise program and reviewing their progress. The patient sees cause-and-effect results in their treatment, which ultimately produces goal-directed actions-a major component in SDet.

Our study showed students with NBPP rated their opportunities at school significantly lower than their opportunities at home (Table 4). This was the most significant disparity in scores taken from the AIR assessment subsets, suggesting that students do not believe their classes and/or school programs support their SDet efforts. Results from similar studies of students with other categories of disabilities support these findings. In a qualitative study by Trainor [23], participants cited "their self-determination efforts had been thwarted in the context of school." In contrast, those students spoke readily about how the development of SDet skills was encouraged and strengthened by their

Table 5

Physical measurements

\begin{tabular}{|c|c|c|c|}
\hline Parameters & $\begin{array}{l}\text { NBPP Group, } \\
\text { Affected Arm }\end{array}$ & $\begin{array}{l}\text { Control Group, } \\
\text { Nondominant Arm }\end{array}$ & $P$ Value \\
\hline \multicolumn{4}{|c|}{ Active range of motion, ${ }^{\circ}$, mean \pm SD } \\
\hline Shoulder forward flexion & $100 \pm 52$ & $180 \pm 0$ & $<.0001$ \\
\hline Elbow flexion & $122 \pm 28$ & $150 \pm 0$ & .0002 \\
\hline Elbow extension & $-25 \pm 28$ & $0 \pm 0$ & .0009 \\
\hline Pronation & $42 \pm 73$ & $90 \pm 0$ & .008 \\
\hline Supination & $44 \pm 48$ & $90 \pm 0$ & .0004 \\
\hline \multicolumn{4}{|c|}{ Grip and pinch strength, lbs, mean \pm SD } \\
\hline Grip & $35 \pm 20$ & $53 \pm 15$ & .002 \\
\hline 3-point pinch & $9 \pm 4$ & $13 \pm 4$ & .006 \\
\hline Lateral pinch & $11 \pm 5$ & $14 \pm 3$ & .01 \\
\hline 9-Hole Peg Test, s, mean \pm SD & $25 \pm 16$ & $20 \pm 2$ & .24 \\
\hline \multicolumn{4}{|c|}{ Manual muscle testing, median MRC score (range) } \\
\hline Anterior deltoid & $2(2-5)$ & $5(2-5)$ & $<.0001$ \\
\hline Biceps & $3(2-5)$ & $5(2-5)$ & $<.0001$ \\
\hline Triceps & $3(2-5)$ & $5(2-5)$ & $<.0001$ \\
\hline \multicolumn{4}{|l|}{ Mallet grade, median grade (range) } \\
\hline Abduction & II (II-IV) & IV & $<.0001$ \\
\hline Exorotation & II (II-IV) & IV & $<.0001$ \\
\hline Hand-to-head & III (II-IV) & IV & $<.0001$ \\
\hline Hand-to-back & II (II-IV) & IV & $<.0001$ \\
\hline Hand-to-mouth & III (II-IV) & IV & $<.0001$ \\
\hline
\end{tabular}

NBPP = neonatal brachial plexus palsy; SD = standard deviation; MRC = Medical Research Council. 
families at home. Other studies consistently reported limited opportunities for students with disabilities to practice SDet at school $[24,25]$. Literature on SDet indicates that SDet develops over time and in multiple settings. Therefore, it is important to provide students with consistent opportunities and support to practice goal-setting, follow through, adjustment of goals, and advocating for themselves as well as the ability to make discerning choices in multiple environments [23,25-27]. In addition to teachers/educators, caregivers, and providers should be aware of the psychosocial context of adolescents with NBPP and that by encouraging personal development and fulfillment SDet can improve, despite physical/functional differences.

Studies show that children with persistent conditions develop coping strategies or "survivor sense" that could ultimately increase their SDet [19,28-30]. During daily activities, children with NBPP might encounter physical challenges, and these challenges could cause frustration, stress, or even social difficulties [19]. Coping strategies, such as social support or the recognition from peers or parents, could mediate the psychosocial impact of their physical impairment [29]. In a similar study that investigated self-concept in youth with NBPP, the authors report that a greater level of social support is associated with better self-concept and fewer social difficulties [19]. It is possible that the positive coping mechanism and social support could reinforce positive psychosocial functioning and actually increase their SDet.

We demonstrate that both NBBP and control adolescents reported greater SDet compared with perception of their parents. This finding is consistent with current literature, which reports discrepancies between children's self-report and parent-proxy across pediatric patient populations [9,31-33]. Studies investigating health-related quality of life reveal that parents and children tend to have greater agreement on physical activities and symptom-related measures; however, parents and children report lower agreement on social or emotional aspects such as peer relations, selfesteem, and mental health [9,31-33]. External factors including physical functioning or visible impairment might be more evident and lead to greater agreement between children and parents, whereas internal factors such as emotional, body image, self-esteem, and SDet are more difficult to perceive and evaluate [34]. In addition, the chronic condition of NBPP also might influence caregivers' psychosocial status and family functioning $[35,36]$. The financial burden and time commitment of clinic appointments might cause stress and disturbance of family routines $[9,35,36]$. Perceptions about their child's potential struggles, guilt, and the heightened awareness of their physical differences could manifest in thinking their child will miss out on opportunities. Therefore, it is unclear whether the impact of NBPP on caregivers and families might affect parent-proxy reporting of SDet scores. Future studies should investigate whether parent-proxy evaluation could truly reflect the impact of NBPP.

\section{Practice Management}

Because the results of our study showed that NBPP participant perceptions of opportunities at school were significantly lower than opportunities at home and that control group results did not indicate a significant difference in those opportunities, further research is needed to determine whether this result is consistent for adolescents with other disabilities and in larger populations. Other studies consistently found that children with disabilities rate their SDet ability greater than teacher ratings for those children. These studies show similar results for high-incident disability categories including learning disabilities, cognitive disability, and emotional/behavioral disability, possibly indicating that fewer opportunities for SDet might be related to the child being disabled and not because of their true ability $[26,37]$. This would suggest the need for further research to analyze what is happening in school programs and with teachers. Some previous research has suggested that there may be insufficient teacher preparation [24,38-41], or that teachers have a preconceived idea that children with disabilities cannot be self-determined $[38,42]$. It would be helpful to analyze both these and other possibilities to explain why youth with disabilities do not believe they have opportunities to practice SDet at school.

\section{Limitations}

Several limitations exist in this study. The sample size is relatively small and homogeneous, as it is derived from a tertiary-care specialty referral center. A convenience sample of control subjects may have narrowed opportunities for a wider variance in responses. The AIR assessment was developed mainly as a self-assessment tool to help educators better understand their teaching practices and how it might impact their students. The assessment usually involves 3 participants - the student, the parent, and the educator. Teachers did not complete any assessments of the students in our study, which could have revealed further perceptions in relationship to SDet opportunities, especially since the NBPP group rated their school opportunities lower than the control group. The wide geographical range of schools attended by the study participants limited our ability to include teacher participation.

\section{Conclusions}

Adolescents with NBPP presented similar SDet levels as their age/gender-matched typically developing peers. These results could be a reflection of our program's patient- and family-centered care approach. 
Therefore, caregivers and providers should encourage adolescents with NBPP to be involved in daily activities and counsel them in ways that could increase their sense of personal development and personal fulfillment. Establishing support systems that include positive coping strategies could also be beneficial for improving SDet skills. Finally, teachers should be aware that opportunities for acquiring SDet skills might be more limited at school than at home in this age group.

\section{References}

1. Chung KC, Yang LJS, McGillicuddy JE, eds. Practical Management of Pediatric and Adult Brachial Plexus Palsies. 1st ed. London, England: Elsevier Saunders; 2012.

2. Foad SL, Mehlman CT, Ying J. The epidemiology of neonatal brachial plexus palsy in the United States. J Bone Joint Surg Am 2008;90:1258-1264.

3. Greenwald AG, Schute PC, Shiveley JL. Brachial plexus birth palsy: A 10 -year report on the incidence and prognosis. J Pediatr Orthop 1984; 4:689-692.

4. Sheffler LC, Lattanza L, Hagar Y, Bagley A, James MA. The prevalence, rate of progression, and treatment of elbow flexion contracture in children with brachial plexus birth palsy. J Bone Joint Surg Am 2012;94:403-409.

5. Benjamin K. Part 2. Distinguishing physical characteristics and management of brachial plexus injuries. Adv Neonatal Care 2005; 5:240-251.

6. Uysal H, Demir SO, Oktay F, Selcuk B, Akyuz M. Extremity shortness in obstetric brachial plexus lesion and its relationship to root avulsion. J Child Neurol 2007;22:1377-1383.

7. Lee BH, Kim YM, Jeong GC. Mediating effects of the ICF domain of function and the gross motor function measure on the ICF domains of activity, and participation in children with cerebral palsy. J Phys Ther Sci 2015;27:3059-3062.

8. Park EY, Kim WH. Relationship between activity limitations and participation restriction in school-aged children with cerebral palsy. J Phys Ther Sci 2015;27:2611-2614.

9. Squitieri L, Larson BP, Chang KW, Yang LJ, Chung KC. Understanding quality of life and patient expectations among adolescents with neonatal brachial plexus palsy: A qualitative and quantitative pilot study. J Hand Surg Am 2013;38:2387-2397.

10. Cavallo S, Majnemer A, Mazer B, Chilingaryan G, Ehrmann Feldman D. Participation in leisure activities among Canadian children with arthritis: Results from a national representative sample. J Rheumatol 2015;42:1002-1010.

11. Ward MJ. The many facets of self-determination; NICHCY transition summary. Washington, DC: National Information Center for Children and Youth with Disabilities; 1988.

12. Field S, Martin J, Miller R, Ward M, Wehmeyer M. A Practical Guide to Teaching Self-Determination. Reston, VA: Council for Exceptional Children; 1998.

13. Field S, Sarver M, Shaw S. Self-determination: A Key to success in postsecondary education for students with learning disabilities. Remedial Spec Educ 2003;24:339-349.

14. McDougall J, Evans J, Baldwin P. The importance of selfdetermination to perceived quality of life for youth and young adults with chronic conditions and disabilities. Remedial Spec Educ 2010;31:252-260.

15. Wolman JM, Campeau PL, DuBois PA, Mithaug DE, Stolarski VS. AIR Self-Determination Scale and User Guide. Palo Alto, CA: American Institutes for Research; 1994.

16. Pearl ML, van de Bunt F, Pearl M, Lightdale-Miric N, Rethlefsen S, Loiselle J. Assessing shoulder motion in children: Age limitations to Mallet and ABC Loops. Clin Orthop Relat Res 2014;472:740-748.
17. Mathiowetz V, Wiemer DM, Federman SM. Grip and pinch strength: Norms for 6- to 19-year-olds. Am J Occup Ther 1986;40:705-711.

18. Smith YA, Hong E, Presson C. Normative and validation studies of the Nine-hole Peg Test with children. Percept Mot Skills 2000;90: 823-843.

19. Mentrikoski JM, Duncan CL, Melanson A, et al. Factors related to the psychosocial functioning of youth with neonatal brachial plexus injuries. J Pediatr Psychol 2015;40:285-296.

20. Strombeck C, Fernell E. Aspects of activities and participation in daily life related to body structure and function in adolescents with obstetrical brachial plexus palsy: A descriptive follow-up study. Acta Paediatr 2003;92:740-746.

21. Harrison LH, Arnold M, Love FE. Empowering student with disabilities by teaching self-determination skills. Education 1997;117:547.

22. Pandey S, Justice D, Chang KWC, Yang LJS. The Interdisciplinary Model: An Effective Approach to Patient Family-Centered Healthcare at a Tertiary Care Specialty Brachial Plexus Program. The Beryl Institute 2015. Available at http://c.ymcdn.com/sites/ theberylinstitute.site-ym.com/resource/resmgr/Grant_Program_ Papers/The_Interdisciplinary_Model.pdf. Accessed March 1, 2015.

23. Trainor AA. Self-determination perceptions and behaviors of diverse students with LD during the transition planning process. J Learn Disabil 2005;38:233-249.

24. Eisenman LT, Chamberlin M. Implementing self-determination activities: Lessons from schools. Remedial Spec Educ 2001;22: 138-147.

25. Shogren KA. Culture and self-determination: A synthesis of the literature and directions for future research and practice. Career Dev Except Individ 2011;34:115-127.

26. Carter EW, Lane KL, Pierson MR, Glaeser B. Self-determination skills and opportunities of transition-age youth with emotional disturbance and learning disabilities. Except Child 2006;72: 333-346.

27. Shogren KA, Palmer SB, Wehmeyer ML, Plotner AJ, Pack Y. Impact of the self-determined learning model of instruction on teacher perceptions of student capacity and opportunity for self-determination. Educ Training Autism Dev Disabil 2014;49:440-448.

28. DeWalt DA, Gross HE, Gipson DS, et al. PROMIS pediatric selfreport scales distinguish subgroups of children within and across six common pediatric chronic health conditions. Qual Life Res 2015;24:2195-2208.

29. Franzblau LE, Chung KC, Carlozzi N, Chin AY, Nellans KW, Waljee JF. Coping with congenital hand differences. Plast Reconstr Surg 2015;135:1067-1075.

30. Maskell J, Newcombe P, Martin G, Kimble R. Psychosocial functioning differences in pediatric burn survivors compared with healthy norms. J Burn Care Res 2013;34:465-476.

31. Eiser C, Morse R. Can parents rate their child's health-related quality of life? Results of a systematic review. Qual Life Res 2001; 10:347-357.

32. Gutierrez-Colina AM, LaMotte J, Eaton C, Kardon P, Blount RL. The role of self-competence in health-related quality of life and behavioral functioning of children with Tourette syndrome. J Dev Behav Pediatr 2015;36:743-751.

33. Tehranian S, Jafari S, Yousofi J, et al. Health-related quality of life (HRQOL) in children with chronic liver disease in North East Iran using PedsQL 4.0. Electron Physician 2015;7:1214-1219.

34. Achenbach TM, McConaughy SH, Howell CT. Child/adolescent behavioral and emotional problems: Implications of crossinformant correlations for situational specificity. Psychol Bull 1987; 101:213-232.

35. Alyanak B, Kilincaslan A, Kutlu L, Bozkurt H, Aydin A. Psychological adjustment, maternal distress, and family functioning in children with obstetrical brachial plexus palsy. J Hand Surg Am 2013;38: 137-142.

36. Louden E, Allgier A, Overton M, Welge J, Mehlman CT. The impact of pediatric brachial plexus injury on families. J Hand Surg Am 2015; $40: 1190-1195$. 
37. Carter EW, Trainor A, Owens L, Sweden B, Sun Y. Selfdetermination prospects of youth with high-incidence disabilities: Divergent perspectives and related factors. J Emot Behav Disord 2010;18:67-81.

38. Mason C, Field S, Sawilowsky S. Implementation of selfdetermination activities and student participation in IEPs. Except Child 2004;70:441-451.

39. Shogren KA. A social-ecological analysis of the self-determination literature. Intellect Dev Disabil 2013;51:496-511.
40. Thoma CA, Williams JM, Davis NJ. Teaching self-determination to students with disabilities: will the literature help? Career Dev Except Individ 2005;28:104-115.

41. Wehmeyer ML, Agran M, Hughes C. A national survey of teachers' promotion of self-determination and student-directed learning. J Spec Educ 2000;34:58-68.

42. Shogren KA, Wehmeyer ML, Palmer SB, et al. Examining individual and ecological predictors of the self-determination of students with disabilities. Except Child 2007;73:488-510.

\section{Disclosure}

D.B. School of Education, Spring Arbor University, Spring Arbor, MI Disclosure: nothing to disclose

L.R. Department of Neurosurgery, University of Michigan, Ann Arbor, MI Disclosure: nothing to disclose

K.W.-C.C. Department of Neurosurgery, University of Michigan, Ann Arbor, MI Disclosure: nothing to disclose
L.J.-S.Y. Department of Neurosurgery, University of Michigan, Ann Arbor, MI Disclosure: nothing to disclose

V.S.N. Department of Physical Medicine and Rehabilitation, University of Michigan, Pediatric Rehabilitation Center, 2205 Commonwealth, Ann Arbor, MI 48105. Address correspondence to: V.S.N.; e-mail: vsnelson@umich.edu Disclosure: nothing to disclose

Funding for this study was provided by the MedSAU Fund.

Submitted for publication August 3, 2016; accepted June 13, 2017. 